\title{
Mitochondrial Dysfunction in Stem Cell Aging
}

\author{
Anna Meiliana ${ }^{1,2, *}$, Nurrani Mustika Dewi², Andi Wijaya ${ }^{2,3}$ \\ ${ }^{1}$ Postgraduate Program in Clinical Pharmacy, Padjadjaran University, Jl. Eijkman No.38, Bandung, Indonesia \\ ${ }^{2}$ Prodia Clinical Laboratory, Jl. Cisangkuy No.2, Bandung, Indonesia \\ ${ }^{3}$ Postgraduate Program in Clinical Biochemistry, Hasanuddin University, Jl. Perintis Kemerdekaan Km.10, Makassar, Indonesia \\ *Corresponding author. E-mail: anna.meiliana@prodia.co.id
}

\section{Abstract}

$\mathrm{B}$ ACKGROUND: Regardless of the precise underlying molecular mechanisms, the fundamental defining manifestation of aging is an overall decline in the functional capacity of various organs to maintain baseline tissue homeostasis and to respond adequately to physiological needs under stress. There is an increasingly urgent need for a more complete understanding of the molecular pathways and biological processes underlying aging and age-related disorders.

CONTENT: Mitochondria constitute the most prominent source of adenosine triphosphate (ATP) and are implicated in multiple anabolic and catabolic circuitries. In addition, mitochondria coordinate cell-wide stress responses and control non-apoptotic cell death routines. The involvement of mitochondria in both vital and lethal processes is crucial for both embryonic and postembryonic development, as well as for the maintenance of adult tissue homeostasis. Age-associated telomere damage, diminution of telomere 'capping' function and associated p53 activation have emerged as prime instigators of a functional decline of tissue stem cells and of mitochondrial dysfunction that adversely affect renewal and bioenergetic support in diverse tissues. Constructing a model of how telomeres, stem cells and mitochondria interact with key molecules governing genome integrity, 'stemness' and metabolism provides a framework for how diverse factors contribute to aging and age-related disorders.

SUMMARY: Cellular senescence defined as an irreversible proliferation arrest promotes age-related decline in mammalian tissue homeostasis. The aging of tissue-specific stem cell and progenitor cell compartments is believed to be central to the decline of tissue and organ integrity and function in the elderly. Taken into consideration that the overwhelming majority of intracellular reactive oxygen species (ROS) are of mitochondrial origin, it is reasonable to posit that the elevated ROS production might be caused by alteration in mitochondrial function during senescence. It is likely that mitochondria and stem cells will remain at the forefront of aging research also for the next decade.

KEYWORDS: aging, stem cell, mitochondrial biogenesis, mitophagy, senescence, telomeres

Indones Biomed J. 2015; 7(1): 15-30

\section{Introduction}

Aging can be defined as 'a progressive, generalized impairment of function, resulting in an increased vulnerability to environmental challenge and a growing risk of disease and death'.(1) It is generally assumed that accumulated damage to a variety of cellular systems is the underlying cause of aging.(2) There is growing appreciation for a more subtle role for oxidative stress in aging. This perspective recognizes the important role of reactive oxygen and nitrogen species in regulating adaptive responses to physiological stress (i.e. redox signaling).(3) One characteristic of this redox signaling is that it typically involves low levels of relatively short-lived oxidative stress under normal physiological conditions. Another important feature of the redox stress hypothesis in the context of aging 
is that the signaling is dynamic and reversible. Mitochondria are likely targets for regulation by redox signaling, because they are a major source of reactive oxygen species (ROS) in most cells. This is supported by reports demonstrating that mitochondrial enzyme activities, metabolic fluxes, and morphology are sensitive to the redox environment ex vivo and in cells.(4)

To preserve genome integrity, cells have developed a fine-tuned machinery to counteract ROS by keeping them in equilibrium with reducing equivalents. $(5,6)$ The maintenance of redox balance is thus critical for cells both in steady states and during adaptations to different conditions. Now, a new study by Ji, et al., demonstrates that supporting redox homeostasis is important also during the induction of pluripotency.(7)

A diminished capacity to maintain tissue homeostasis is a central physiological characteristic of aging. As stem cells regulate tissue homeostasis, depletion of stem cell reserves and/or diminished stem cell function have been postulated to contribute to aging.(9) It has further been suggested that accumulated DNA damage could be a principal mechanism underlying age-dependent stem cell decline. $(10,11)$ Multiple lines of evidence indicate that mitochondrial ROS also influence homeostatic signaling pathways to control cell proliferation and differentiation and to contribute to adaptive stress signaling pathways, such as hypoxia.(12) Observations from premature aging mouse models suggest that hematopoietic progenitors are especially sensitive to ROS and/or redox state changes that promote proliferation and prevent quiescence. $(13,14)$ These observations imply that ROS/redox signaling affects somatic stem cell function and causes progeroid symptoms (15) and that mitochondrial dysfunction in somatic stem cells may contribute to aging-related degeneration.(16)

Increasing evidence points to telomeres and p53mediated DNA damage signaling being core components that drive the senescent or apoptotic depletion of tissue stem-cell reserves and age-related tissue degeneration. (17) A speculative model that posits a connection linking telomere damage and p53 activation with stem-cell and mitochondrial dysfunction. This model offers a unifying explanation of how telomeres influence the health of the aging organism across diverse tissues with wide-ranging proliferative profiles.(17)

\section{Stem Cell Hypothesis of Aging}

The complexity of the aging process does not allow for a single all-encompassing definition, yet decades of study using diverse systems, methodologies, and model organisms have begun to build a consensus regarding the central physiological characteristics of aging. Indeed, such studies have shown that the process of aging is invariably accompanied by a diminished capacity to adequately maintain tissue homeostasis or to repair tissues after injury. When homeostatic control diminishes to the point at which tissue/organ integrity and function are no longer sufficiently maintained, physiologic decline ensues, and aging is manifested. Consistent with this, many of the pathophysiological conditions afflicting the elderly, such as anemia, sarcopenia (loss of muscle mass), and osteoporosis, suggest an imbalance between cell loss and renewal. The fact that homeostatic maintenance and regenerative potential of tissues wane with age has implicated stem cell decline as a central player in the aging process.(18)

Most tissues and organs contain minor populations of primitive stem cells and progenitor cells. These cells are integral first in the developing fetus for the generation of tissues and organs and later in the adult for ongoing tissue maintenance and regeneration after injury. In general, they have slow turnover and reside in specialized niches, protected from the environment, so that only a few are activated at a time. Thus, stem cells are a defense against aging, replacing cells lost through attrition. If the rejuvenating effect of stem cells were perfect, senescing cells would be replaced indefinitely; but even in highly regenerative tissues such as the skin, the gut, and the hematopoietic system, age - related decline in function is well established.(19) Still unclear are the effects of aging on the stem cells themselves, which could contribute to inferior tissue repair.(20)

Recent evidence supports the model that stem cells in several tissues are largely retained in a quiescent state but can be coaxed back into the cell cycle in response to extracellular cues, even after prolonged periods of dormancy. Once stimulated to divide, stem cells yield undifferentiated progeny, which in turn produce differentiated effector cells through subsequent rounds of proliferation. This 'hierarchical' differentiation scheme makes sense from the perspective of organismal longevity - it permits the production of large numbers of differentiated cells from a single stem cell by combining subsequent steps in differentiation with proliferation.(21,22) Therefore, this approach balances the high rates of homeostatic proliferation that are required in tissues like the bone marrow and intestine with the long-term need to protect stem cells from mutagenic insult and carcinogenesis.(23)

Additionally, as stem cells appear to be less metabolically active in their quiescent state, they may 
be subjected to lower levels of DNA-damage-inducing metabolic side products such as ROS.(24) It is therefore reasonable to surmise that perhaps some characteristics of aging - once thought to be degenerative - might reflect a decline in the regenerative capacity of resident stem cells across many different tissues. Self-renewal comes with some danger for the organism; in particular, a risk of malignant transformation.(25-27)

This relationship between self-renewing cells and cancer raises the possibility that while carrying out a beneficial, anti-cancer function these tumor-suppressor mechanisms may inadvertently contribute to aging by causing stemcell arrest or attrition.(23) In summary, we believe the data suggest that we grow old partly because our stem cells grow old as a result of mechanisms that suppress the development of cancer over a lifetime. In this regard, our self-renewing stem cells appear to grow old because of heritable intrinsic events, such as DNA damage, but also due to cell-extrinsic events such as alterations in their supporting niches. Anticancer mechanisms such as senescence and apoptosis, which rely on telomere shortening and/or p53 and p16INK4a activation, appear to promote aging just as their failure is associated with cancer.(23)

\section{Mitochondria Control Cellular Life, Stress and Death}

The central player in bioenergetics is the mitochondrion. Mitochondria produce about $90 \%$ of cellular energy, regulate cellular redox status, produce ROS, maintain $\mathrm{Ca}^{2+}$ homeostasis, synthesize and degrade high-energy biochemical intermediates, and regulate cell death through activation of the mitochondrial permeability transition pore (mtPTP). The mitochondrial genome consists of thousands of copies of the maternally inherited mitochondrial DNA (mtDNA) plus between 1,000 and 2,000 nuclear DNA (nDNA) genes. mtDNA codes for 13 oxidative phosphorylation (OXPHOS) polypeptides, plus the 22 transfer RNA (tRNA) and the $12 \mathrm{~S}$ and $16 \mathrm{~S}$ ribosomal RNAs (rRNAs) necessary for the bacteria-like mitochondrial protein synthesis. mtDNA polypeptides encompass seven of the 45 polypeptides of OXPHOS complex I (ND1, ND2, ND3, ND4, ND4L, ND5, and ND6), one of the 11 polypeptides of complex III (cytochrome b), three of the 13 polypeptides of complex IV (COI, COII, and COIII), and two of the approximated 17 poly-peptides of complex $\mathrm{V}$ (ATPase6 and ATPase8). Complexes I, III, and IV constitute the electron transport chain (ETC), which oxidizes the reducing equivalents (hydrogen-derived electrons) from food with the oxygen we breathe.(29)

Alterations in mitochondrial structure and function can impair OXPHOS, which in turn can reduce energy production, alter cellular redox state, increase ROS production, deregulate $\mathrm{Ca}^{2+}$ homeostasis, and ultimately activate the mtPTP, leading to apoptosis. These and other consequences of OXPHOS perturbation can destabilize mtDNA. This results in progressive accumulation of somatic mtDNA mutations and decline of mitochondrial function, which accounts for aging and the delayed-onset and progressive course of degenerative diseases. As energy output declines, the most energetic tissues are preferentially affected, resulting in degenerative diseases of the central nervous system, heart, muscle, and kidney. Aberrant mitochondrial caloric metabolism also leads to metabolic deregulation, endocrine dysfunction, and symptoms such as diabetes, obesity, and cardiovascular disease.(29)

In essence, mitochondria occupy a key position in the management of several cellular functions, including physiological metabolism, stress responses, and cell death. Intriguingly, several mitochondrial components that operate as cell death regulators also exert cell death-unrelated functions. $(31,32)$ This might reflect the evolutionary origin of mitochondria (which, according to the endosymbiotic hypothesis, have evolved from proteobacteria engulfed by protoeukaroytic cells) (33) or their need to centralize a

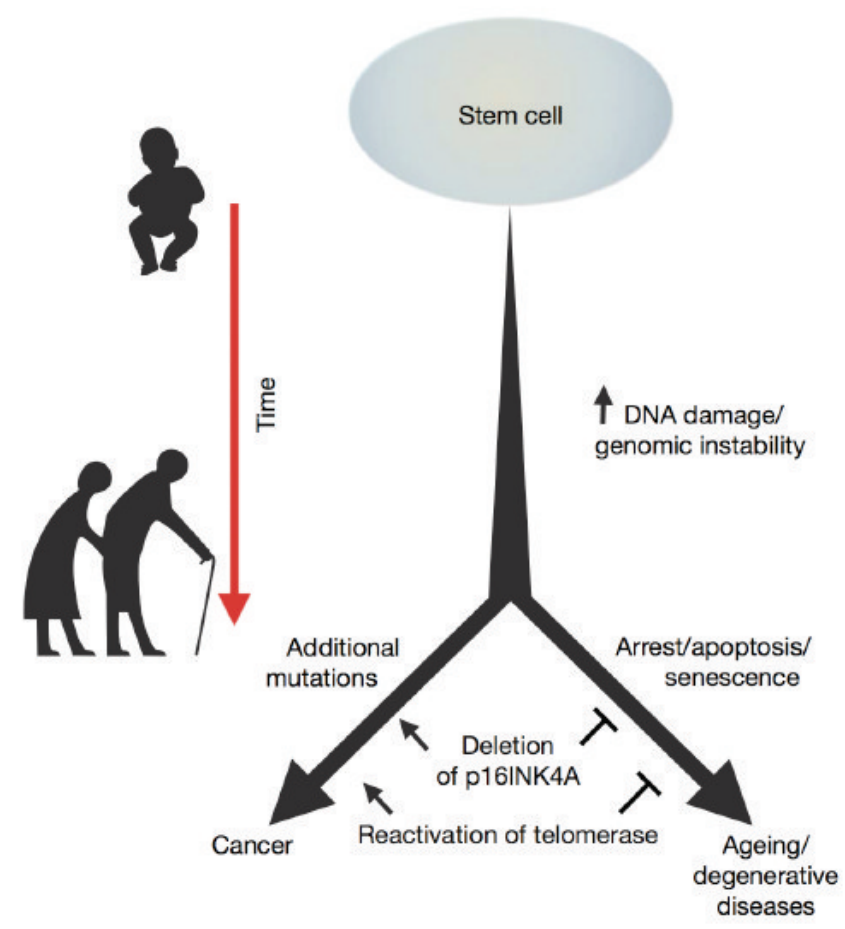

Figure 1. A stem cell perspective on cancer and aging.(28) (Adapted with permission from Nature Publishing Group). 
wide array of molecular functions within a relatively small number of proteins (32).

In adverse conditions, cells activate a wide array of mechanisms to re-establish homeostasis and to repair stressinduced molecular damage.(34) Mitochondria are involved in the response of cells to a wide number of perturbations, including oxidative stress and pathogen invasion. In addition, mitochondria play a critical role during autophagy in that they both can be the substrate of autophagic degradation (mitophagy) (35) or can be specifically spared by the autophagic machinery to ensure energy production during stress responses $(36,37)$. Thus, ROS constitute a normal side product of respiration, they are required for several intracellular signaling pathways (38), and are normally handled by an entire battery of mitochondrial, cytosolic, and peroxisomal antioxidant systems, including the following: superoxide dismutases, which catalyze the dismutation of superoxide anions $\left(\mathrm{O}_{2}^{-}\right)$into $\mathrm{O}^{2}$ and hydrogen peroxide $\left(\mathrm{H}_{2} \mathrm{O}_{2}\right)$; catalases, which catalyze the decomposition of $\mathrm{H}_{2} \mathrm{O}_{2}$ into $\mathrm{H}_{2} \mathrm{O}$ and $\mathrm{O}_{2}$; peroxiredoxins, which reduce $\mathrm{H}_{2} \mathrm{O}_{2}$ as well as other oxidized species such as organic hydroperoxides and peroxynitrites; thioredoxin, acting as an efficient reducing agent, thanks to a highly conserved CXXC motif that can be restored by thioredoxin reductase; glutathione, a tripeptide with intrinsic antioxidant properties that can be recycled on reduction by glutathione reductase; glutathione peroxidase, an enzyme that uses the reducing equivalents of glutathione for converting $\mathrm{H}_{2} \mathrm{O}_{2}$ into $\mathrm{H}_{2} \mathrm{O}$ and organic hydroperoxides into the corresponding alcohols; and, simply, thiol containing proteins, which are endowed with the capacity to buffer ROS by forming oxidized disulfide bonds.(39)

As a consequence of oxidative stress, be it endogenous (i.e., at tributable to self-generated ROS) or exogenous (i.e., attributable to extracellular ROS), mitochondria undergo several functional adaptations. These adaptations maximize the ROS-buffering capacity of mitochondria (and of other cellular compartments), thus allowing the re-establishment of homeostasis in response to mild oxidative stress. However, if oxidative stress persists and the associated molecular damage (i.e., lipid peroxidation, protein misfolding, mtDNA mutations) is beyond recovery, then mitochondria can translate such an adaptive response into the activation of cell death.(40)

Mitochondria have been shown to control (at least) 3 distinct cell death modalities: (A) extrinsic apoptosis; (B) intrinsic apoptosis; and (C) regulated necrosis. Extrinsic apoptosis is ignited by either the ligand-induced oligomerization of transmembrane proteins of the death receptor superfamily (e.g., FAS/CD95, tumor necrosis factor receptor 1 (TNFR1)) (41) or when the extracellular concentrations of specific trophic factors (e.g., netrin-1) fall below a certain threshold, leading to the transduction of lethal signals by the so-called dependence receptors (e.g., unc-5 homolog A (C. elegans) (UNC5A), deleted in colon cancer (DCC)).(42) On oligomerization, the cytoplasmic tails of death receptors drive the assembly of a multiprotein complex known as death-inducing signaling complex, eventually leading to the activation of the proapoptotic caspase-8-caspase- 3 cascade.(43)

Intrinsic apoptosis involves a central step of regulation that is mediated by mitochondria. Thus, in response to multiple distinct intracellular stress conditions, mitochondrial membranes can become permeabilized because of the pore-forming activity of proapoptotic members of the B-cell lymphoma-2 (Bcl-2) protein family, such as $\mathrm{Bcl}-2$-associated $\mathrm{X}$ protein $(\mathrm{Bax})$ and Bcl-2 homologous antagonist killer (Bak). Alternatively, mitochondria can lose their structural integrity after the so-called mitochondrial permeability transition (MPT), a phenomenon that is initiated at the mitochondrial inner membrane. In both cases, permeabilized mitochondria allow for the release of potentially toxic proteins into the cytoplasm, including cytochrome c (Cyt c). Together with deoxyadenosine triphosphate (dATP) and the adaptor protein apoptotic peptidase-associated factor 1 (APAF1), cytoplasmic Cyt c drives the assembly of the so-called apoptosome, a supramolecular complex for the activation of pro-caspase-9. Eventually, active caspase-9 proteolytically processes pro-caspase-3, resulting in the execution of apoptotic cell death.

One particular instance of regulated necrosis, also known as necroptosis, is triggered by TNFR1 ligation when caspases (in particular caspase-8) are inactive (for instance because of the presence of the caspase inhibitor Z-VADfmk). In these conditions, receptor interacting protein kinase (RIPK)1 and RIPK3 engage in physical and functional interactions with mixed lineage kinase domain-like (MLKL) to form a multiprotein complex called necrosome. (44-49) The necrosome stimulates regulated necrosis at the mitochondrial level by inhibiting adenine nucleotide transferase (ANT), by exacerbating glutaminolysis (and, hence, inducing the overgeneration of ROS), and by promoting mitochondrial fragmentation.(40) Thus, with a relatively small number of proteins, mitochondria operate as highly specialized cellular sentinels that continuously monitor the conditions of the cell to finely adapt its metabolic activity, to coordinate adaptive responses to stress, and to decide on its final and inexorable fate. 


\section{Mitochondrial Biogenesis and Mitophagy}

Cell function relies on the constant supply of ATP and it is crucial that mitochondrial ATP production adapts to environmental and cellular challenges to maintain cellular function. Key molecules in sensing cellular stress situations seem to be the peroxisome proliferator-activated receptor-c coactivator (PGC)-family of transcriptional co-activators, which are key regulators of mitochondrial biogenesis. Recent work has identified several stressregulated pathways that affect mitochondrial biogenesis through modulation of the activity of PGC-1 $\alpha .(50)$ Mitochondrial biogenesis can be defined as the growth and division of pre-existing mitochondria. According to the well-accepted endosymbiotic theory, mitochondria are the direct descendants of an $\alpha$-proteobacteria endosymbiont that became established in a host cell. Due to their ancient bacterial origin, mitochondria have their own genome and a capacity for autoreplication. Mitochondrial proteins are encoded by the nuclear and the mitochondrial genomes.(51)

Mitochondrial biogenesis is very complex and requires numerous processes: besides synthesis of mtDNA encoded protein, biogenesis of new organellar structures includes synthesis and import of nuclear encoded proteins, assembly of the dual genetic origin derived proteins and mtDNA replication. Mitochondrial biogenesis relies on the concerted and synchronized action of these processes.
(52) Correct mitochondrial biogenesis relies on the spatiotemporally coordinated synthesis and import of $\sim 1000$ proteins encoded by the nuclear genome, of which some are assembled with proteins encoded by mtDNA within newly synthesized phospholipid membranes of the inner and outer mitochondrial membranes. In addition, mtDNA replication and mitochondrial fusion and fission mechanisms must also be coordinated.(51) Mitochondrial biogenesis is triggered by environmental stresses such as exercise, cold exposure, caloric restriction (CR) and oxidative stress, cell division and renewal, and differentiation. The biogenesis of mitochondria is accompanied by variations in mitochondrial size, number, and mass.

Mitochondrial biogenesis thus involves an intricate, complicated network of transcription factors nuclear respiratory factors (NRF)/peroxisome proliferator-activated receptors (PPAR)/estrogen-related receptors (ERR) that activate target genes encoding enzymes of fatty acid oxidation (FAO), OXPHOS, and anti-oxidant defence. PGC-1 $\alpha$, by co-activating, and controlling the expression of this network, directly links external physiological stimuli to the regulation of mitochondrial biogenesis and function. Additionally, mitochondrial biogenesis involves fusion/ fission and requires protein import and processing and cardiolipin biosynthesis. $(53,54)$

Mitochondria in the cells of most tissues are tubular, and dynamic changes in morphology are driven by fission, fusion, and translocation.(55) The ability to undergo fission/

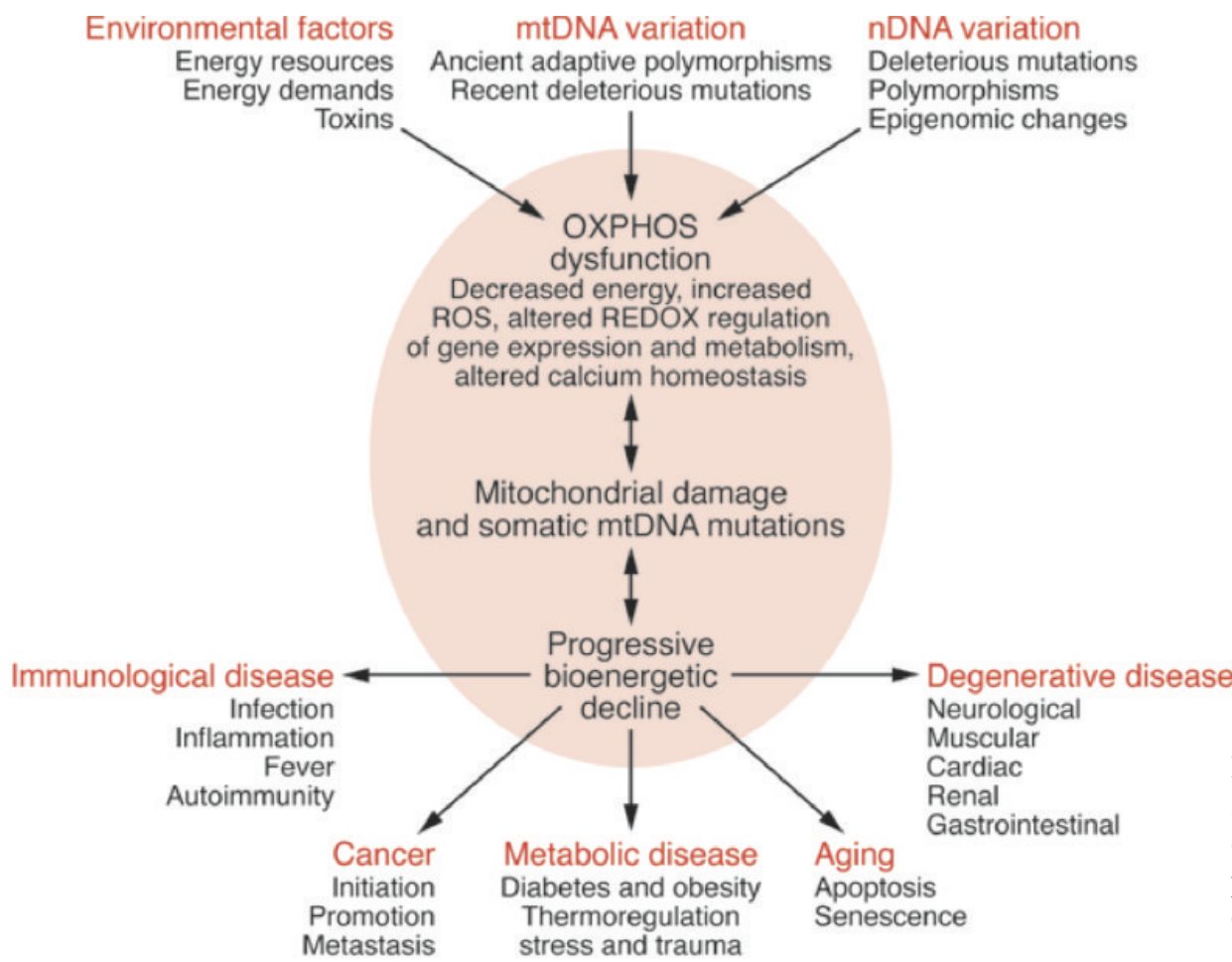

Figure 2. Bioenergetic paradigm for metabolic and degenerative diseases, cancer, and aging.(30) (Adapted with permission from American Society for Clinical Investigation). 
fusion enables mitochondria to divide and helps ensure proper organization of the mitochondrial network during biogenesis. The processes of fission/fusion are controlled by GTPases, most of which were identified in genetic screens in yeast. $(56,57)$ Mitochondrial fission is driven by dynaminrelated proteins (DRP)1 and optic atrophy (OPA)1, while mitochondrial fusion is controlled by mitofusins (Mfn)1 and -2. Mfn are highly expressed in heart and skeletal muscle, and their expression is induced during myogenesis and physical exercise. $(58,59)$ In addition to the control of the mitochondrial network, Mfn2 also stimulates the mitochondrial oxidation of substrates, cell respiration, and mitochondrial membrane potential, suggesting that this protein may play an important role in mitochondrial metabolism, and as a consequence, in energy balance.(58)

Autophagy is a tightly regulated catabolic process whereby cells degrade their constituents to dispose of unwanted cytoplasmic elements and recycle nutrients for cellular remodeling.(60) The mitochondrion is an important actor in the life of a eukaryotic cell, but, like all good actors, a mitochondrion needs to exit the stage at the right time. Mitophagy removes mitochondria once they have played their part.(61) Thus, like macroscopic energy sources and power plants, these microscopic power supplies are essential but prone to release hazardous materials, particularly when they have been compromised by damage or age. Accordingly, ensuring proper elimination of dysfunctional mitochondria is imperative to cellular survival, and mitochondrial damage has been implicated in aging, diabetes, and neurodegenerative diseases.(62) To prevent cellular damage by preserving a population of healthy mitochondria, several quality control mechanisms have evolved.(61)

Several proteins are now identified that are critical in directing autophagosomes to the mitochondria, including autophagy-related gene (ATG)32, Nix, p62, PINK1, and Parkin. Ubiquitination of the mitochondrion, and/ or the interaction of a mitochondrial receptor with the

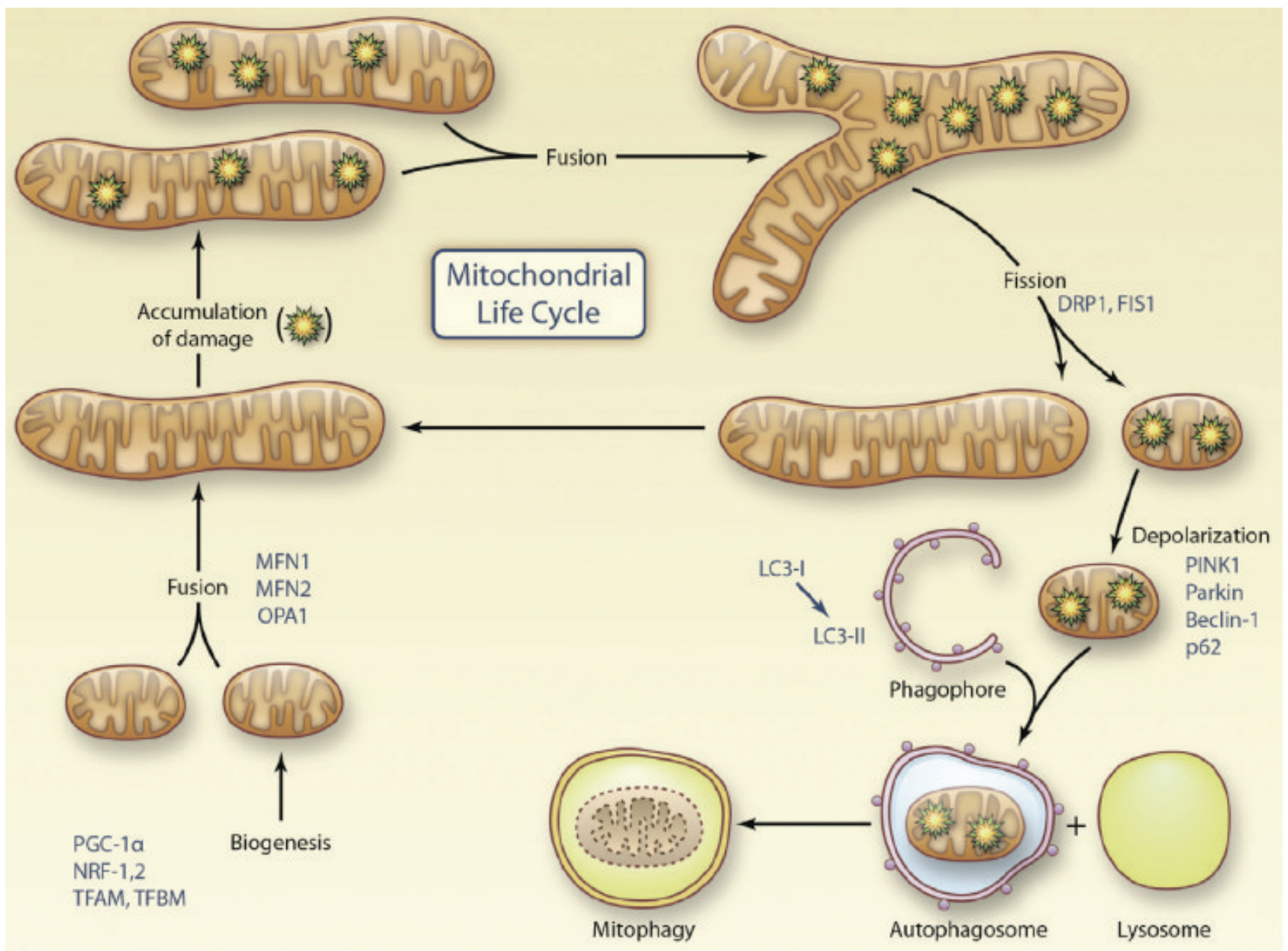

Figure 3. Conceptual illustration of the mitochondrial life cycle and the contribution of mitochondrial dynamics and mitophagy to quality control.(29) (Adapted with permission from American Heart Association). 
autophagosomal protein light chain (LC)3 appear to be important in targeting of the autophagosome, but in each case the details of this recruitment remain unclear.(61)

\section{Mitochondrial Dysfunction and Age-related Diseases}

Mitochondria play important roles in a myriad of cellular processes including ATP production via OXPHOS, biosynthetic pathways, cellular redox homeostasis, ion homeostasis, oxygen sensing, signaling, and regulation of programmed cell death. Mitochondrial dysfunction is central to theories of aging, because age-related changes of mitochondria are likely to impair a host of cellular physiological functions in parallel and contribute to the development of all common age-related diseases.(63)

Mitochondria are highly dynamic organelles, and dysregulation of mitochondrial turnover is likely one of the intrinsic causes of mitochondrial dysfunction, which contributes to dysregulation of cell metabolism, oxidative stress, and altered signal transduction. Mitochondrial ROS might attack various mitochondrial constituents, causing mtDNA mutations and oxidative damage to respiratory enzymes. A defect in mitochondrial respiratory enzymes would increase mitochondrial production of ROS, causing further mitochondrial damage and dysfunction, leading to further decline in cellular and organ function that can eventually progress to death.(39)

The molecular mechanisms underlying agerelated increases in mitochondrial oxidative stress in the cardiovascular system are multifaceted and likely involve cell-autonomous effects, including a significant decline in reduced glutathione content (64), dysregulation of antioxidant defense mechanisms eg, peroxynitrite-mediated nitration and inhibition of manganese superoxide dismutase (MnSOD) (65), and a dysfunctional ETC (66).

There is a significant age-related increase in nicotinamide adenine dinucleotide phosphate (NADPH) oxidase activity both in heart and vasculature (67), which is likely to exacerbate mitochondrial oxidative stress in aging. In addition to the aforementioned age-related mechanisms, several cardiovascular risk factors, including oxidatively modified lipoproteins, cigarette smoke constituents (68), high methionine diet and hyperhomocysteinemia, and diabetes (69), either directly or indirectly may increase ROS production in mitochondria of vascular cells and cardiac myocytes. Recent studies suggest that age-related changes in endocrine/paracrine regulatory mechanisms, including activation of the renin-angiotensin-aldosterone system, adrenergic signaling, and an age-related dysfunction of growth hormone/insulin-like growth factor (IGF)1 signaling, also have an important role in promoting mitochondrial oxidative stress in the aged cardiovascular system.(63)

Neurodegenerative diseases are a large group of disabling disorders of the nervous system, characterized by the relative selective death of neuronal subtypes. In most cases, there is overwhelming evidence of impaired mitochondrial function as a causative factor in these diseases. More recently, evidence has emerged for impaired mitochondrial dynamics (shape, size, fission-fusion, distribution, movement etc.) in neurodegenerative diseases such as Parkinson's disease (PD), Huntington's disease (HD), amyotrophic lateral sclerosis (ALS), and Alzheimer's disease (AD).(70)

mtDNA that encodes 13 of the 92 polypeptides of the OXPHOS system; the remaining structural polypeptides and assembly factors are encoded by nDNA. Mutations in either mtDNA or nDNA, resulting in OXPHOS dysfunction, are particularly known to affect tissues with high energy demands such as the central nervous system, skeletal muscle, and heart. Mitochondria are thought to contribute to aging through the accumulation of mtDNA mutations and net production of ROS. mtDNA mutations, mitochondrial abnormalities, and mitochondrial respiratory chain-deficient cells are also present in age-related neurodegenerative diseases such as PD and AD.(71-77)

PGC- $1 \alpha$ is a transcriptional coactivator that is a central inducer of mitochondrial biogenesis in cells. Recent work highlighted that PGC- $1 \alpha$ can also modulate the composition and functions of individual mitochondria. Therefore, it is emerging that PGC- $1 \alpha$ is controlling global oxidative metabolism by performing two types of remodelling: cellular remodelling through mitochondrial biogenesis and organelle remodelling through alteration in the intrinsic properties of mitochondria. The elevated oxidative metabolism associated with increased PGC$1 \alpha$ activity could be accompanied by an increase in ROS that are primarily generated by mitochondria. However, increasing evidence suggests that this is not the case, as PGC- $1 \alpha$ is also a powerful regulator of ROS removal by increasing the expression of numerous ROS-detoxifying enzymes. Therefore, PGC- $1 \alpha$, by controlling both the induction of mitochondrial metabolism and the removal of its ROS by-products, would elevate oxidative metabolism 
and minimize the impact of ROS on cell physiology.(78)

Several studies also support a protective role for PGC$1 \alpha$ in PD. PD is characterised by the loss of dopaminergic neurons in the substantia nigra and the presence of inclusions, referred to as Lewy bodies, which contain a-synuclein and ubiquitin.(79) The expression of numerous PGC-1 $\alpha$ target genes, such as those of the respiratory chain, is decreased in Parkinson's disease patients.(80) In support of this observation, Ppargc1a-null mice are more sensitive to methyl phenyl tetrahydropyridine (MPTP), a drug used to model PD in experimental studies.(81) Furthermore, PGC$1 \alpha$ protects against neuronal loss in cell culture models of PD. $(82,83)$

PGC-1 $\alpha$ has also been implicated in AD, ALS and Duchenne muscular dystrophy. Expression of PGC-1 $\alpha$ is reduced in $\mathrm{AD}$ patients and in the transgenic 2576 mouse model of AD.(84-86) Importantly, ectopic expression of PGC-1 $\alpha$ in cell models of $\mathrm{AD}$ ameliorates their phenotype. $(84,85)$ In ALS, it has been shown that PGC- $1 \alpha$ improves the overall phenotype of various mouse models of ALS. (86-88) Lastly, PGC-1 $\alpha$ has been shown to regulate the expression of neuromuscular junction genes, such as utrophin and laminin, as well as decrease damage to muscle tissue in a mouse model of Duchenne muscular dystrophy. (89) Overall, these data highlight a potential protective role for PGC-1 $\alpha$ in different neurodegenerative conditions.

Age-associated decrease in the respiratory chain capacity was reported in various tissues, such as skeletal muscle (90) and liver (91). Hypotheses were put forward that acquired mutations of mtDNA would increase with time and segregate in mitotic tissues to eventually cause decline of respiratory chain function leading to age-associated degenerative disease and ageing. $(2,92)$

\section{Mitochondrial Dysfunction and Stem Cell Aging}

Aging-associated decline is consistent across tissues, resulting in slower wound healing, reduced muscle mass and neurogenesis, hair loss, and changes in blood cell type distribution.(93) Tissue homeostasis and regeneration depends on resident progenitor cell function and availability, and is consistent with the observation that genetic depletion of tissue-specific progenitors results in premature aging. (17) Accumulation of genomic and mtDNA mutations place cellular functions at risk and are correlated with aging. Elevated mtDNA mutation rates decrease lifespan, impair stem cell self-renewal, and induce abnormal lineage differentiation during embryogenesis, which manifests as progeria and respiratory chain deficiency. (15) Aging-associated signaling pathways can also induce mitochondrial dysfunction and increase generation of ROS that compromise stem cell proficiency, which can be blunted with the use of antioxidants.(17) The systemic environment also significantly impacts the function of resident stem cells, with muscle and liver cells rejuvenated to a more youthful state when exposed to a young environment, and young cells adopting an aged phenotype in response to an aged environment. $(93,94)$

Metabolism supports fundamental processes throughout life, as cells require a continuous yet adaptable energy supply to meet the demands of their specialized functions. Metabolic flexibility fuels divergent stem cell fates, which include quiescence to minimize stress damage, proliferation and self-renewal to maintain progenitor pools, and lineage specification for tissue regeneration. These vital processes are powered through the metabolism of energy substrates supplied by the environment, such as glucose, fatty acids, and amino acids.(95) Beyond providing energetic supply, metabolic circuits engage master genetic programs in control of cell behavior, with cellular identity and functional state reflecting the specific metabolic pathways being used.(95)

Plasticity in energy metabolism allows stem cells to match the divergent demands of self-renewal and lineage specification. Beyond a role in energetic support, new evidence implicates nutrient-responsive metabolites as mediators of crosstalk between metabolic flux, cellular signaling, and epigenetic regulation of cell fate. Stem cell metabolism also offers a potential target for controlling tissue homeostasis and regeneration in aging and disease. (95)

Embryonic stem cell (ESC)-based cardiac differentiation was used as a paradigm to ascertain the metabolic requirements for tissue specification. Study by Chung ,et al., demonstrated that mitochondrial network maturation integrated with energy-consuming excitationcontraction coupling is mandatory for securing functional progeny of a cardiac lineage. These findings contribute novel insight into the vital role of energetic circuits in genomic reprogramming during cardiac differentiation, establishing metabolic targets for directed cardiogenesis and regeneration.(96) Thus, the state of mitochondrial physiology is an important determinant of developmental competence influencing the outcome of the differentiation process.(97) 
Stimulation of mitochondria biogenesis can overcome the differentiation block in fast-dividing cells, while reducing mitochondrial content perturbs cardiomyocyte differentiation in slow-dividing cells.(98) Mitochondrial and metabolic infrastructure thus prime stem cells for differentiation. When induced to differentiate, ESC and mesenchymal stem cell (MSC) downregulate stemness genes and stimulate mtDNA replication in support of mitochondrial biogenesis and maturation of extensive and interconnected networks of elongated and cristae-rich mitochondria.(96,76,99-101) In parallel, upregulation of tricarboxylic acid (TCA) cycle enzymes and ETC subunits, and downregulation of glycolysis, increases mitochondrial capacity, enabling accelerated respiration and more efficient
ATP production. $(96,102)$ Transition from glycolysis to mitochondrial oxidative metabolism and maintenance of mitochondrial electron transport function is critical for differentiation.

Nutrient-sensitive signaling pathways that regulate lifespan and energy metabolism, such as those mediated by AMP-activated protein kinase (AMPK), forkhead box O (FOXO), insulin/IGF-1, and Mammalian Target of Rapamycin (mTOR), impact stem cell function. $(103,104)$ Stemness is maintained in response to signals of plenty (insulin signaling and abundant amino acids), while signal reduction during starvation induces differentiation.(105) Inhibition of mTOR with rapamycin extends lifespan of mice and restores self-renewal and hematopoiesis of

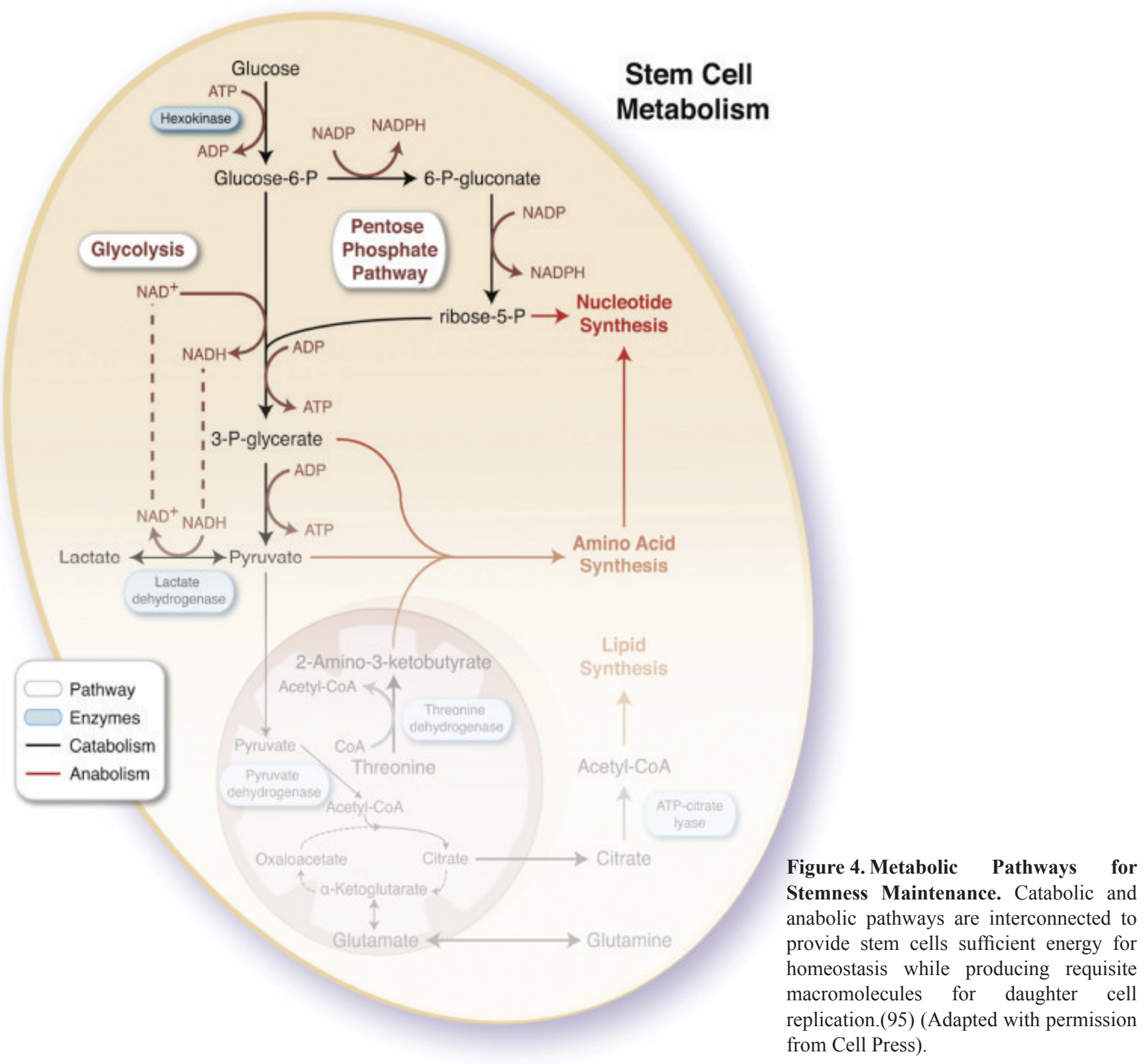


aged hematopoietic stem cell (HSC).(106,107) Signaling pathways that regulate aging and stem cell function may collectively converge on energy metabolism, which functions as a rheostat to regulate self-renewal and differentiation.

AMPK enhances situin (SIRT)1 activity by increasing cellular nicotinamide adenine dinucleotide (NAD)1 levels, resulting in the deacetylation and modulation of the activity of downstream SIRT1 targets that include the PGC-1 $\alpha$ and the FOXO1 and FOXO3 $\alpha$ transcription factors. The AMPK-induced SIRT1-mediated deacetylation of these targets explains many of the convergent biological effects of AMPK and SIRT1 on energy metabolism. AMPK is a critical regulator of mitochondrial biogenesis in response to energy deprivation. Although the mechanisms by which AMPK modulates mitochondrial gene expression are not entirely elucidated, they seem to require the PGC- $1 \alpha$, either by increasing its expression or direct phosphorylation. Because PGC-1 $\alpha$ is also activated by SIRT1-mediated deacetylation, that AMPK alters PGC- $1 \alpha$ activity by changing its acetylation status.(108-116)

FOXOs are important in maintaining the long-term regenerative potential of the HSC compartment, and that analysis of the role of FOXOs in other adult stem cell and ESC compartments may yield insights into the physiology and diseases of the renewing organ systems of long-lived species, including humans.

Senescence represents a stress response in which cells withdraw from the cell cycle and lose the capability to proliferate in response to growth factors or mitogens. $(117,118)$ Senescent cells show very distinctive changes in morphology, acquiring a typical flat and enlarged shape and increase expression of recognized biomarkers of senescence, including staining for $\beta$-galactosidase at $\mathrm{pH}$ of 6.0 (senescence-associated- $\beta$-gal or SA- $\beta$-gal), decreased replicative capacity, increased expression of p53, p21, p16.

The constant regeneration of somatic tissues leads to accumulation of senescent cells, which limits tissue renewal, perturbs normal tissue homeostasis and ultimately elicits aging. The senescence pathway can be triggered by multiple mechanisms. Originally, it was associated with replication exhaustion at the end of the cellular lifespan, a process currently defined as replicative senescence.(119) p53 functions as a transcription factor involved in cell-cycle control, DNA repair, apoptosis and cellular stress responses. However, besides inducing cell growth arrest and apoptosis, p53 activation also modulates cellular senescence and organismal aging.(119)

Genotoxic stress brought about by telomere attrition, impaired DNA repair, ultraviolet (UV) radiation, ionizing radiation (IR), chemicals, ROS and other mechanisms activates p53 and induces cellular growth arrest (in proliferating compartments), senescence or apoptosis. p53 can impair mitochondrial function either directly or indirectly (through regulation of ROS-detoxifying enzymes). This p53-mediated mitochondrial dysfunction triggers a cycle of DNA damage, p53 activation, mitochondrial compromise and increased ROS levels leading to additional DNA damage, and so on. The mitochondrial compromise could contribute to organ dysfunction through decreased ATP generation, as well as changes in mitochondrial metabolism. The interplay between $\mathrm{p} 53$ and other pathways implicated in aging is also indicated. CR activates SIRT1, which decreases p53 activity. Also, SIRT1 (and possibly SIRT6) activates PGC-1 $\alpha$ and boosts mitochondrial biogenesis.(120) PGC- $1 \alpha$ increases antioxidant defence through upregulation of antioxidants (81), whereas p53 has been shown to increase or decrease the expression of antioxidants depending on cellular ROS concentrations (121). B-lymphoma Moloney murine leukemia virus insertion region-1 (Bmi1) loss has been shown to induce mitochondrial dysfunction directly and induce upregulation of p16/ARF.(122,123) ARF increases p53 activity through interaction with mouse double minute 2 homolog (MDM2), the negative regulator of p53.(17)

Applying regenerative metabolism principles to rejuvenate stem cell metabolism has the potential to deterministically alter the fate of differentiating tissues for improved function and repair capacity in aging and/ or disease. As a paradigm of metabolic repair, MSCs demonstrate a capacity to transfer mitochondria and rescue aerobic respiration in cells lacking mitochondria.(124) Mitochondrial transfer has also been observed during stem cell therapy following lung injury, resulting in elevated alveolar ATP levels, which contributes to protection and repair of pulmonary alveoli.(125) Next-generation regenerative platforms with optimized stem cell metabolism will thus be equipped to titrate metabolic competencies and accordingly regenerate tissues and organs.

$\mathrm{CR}$ boosts the number and myogenic function of skeletal muscle stem cells, which is associated with the expression of the metabolic regulators SIRT1 and FOXO3 $\alpha$, mitochondrial biogenesis, and enhanced oxidative metabolism at the expense of glycolysis.(126) The way stem cells use energy and intermediate metabolites determines their prospects. Metabolic regimes shape selfrenewal proficiency, and fuel interconversion of versatile lineage identities. The orchestrated commissioning and decommissioning of metabolic pathways enables stem 
cell differentiation, and also supports reacquisition of pluripotency.(95)

SIRTs are a highly conserved family of NAD1dependent enzymes that regulate lifespan in lower organisms. Recently, the mammalian SIRTs have been connected to an ever widening circle of activities that encompass cellular stress resistance, genomic stability, tumorigenesis and energy metabolism.

SIRT1 through its regulation of PPAR $-\gamma$ and PGC- $1 \alpha$ activity has a significant regulatory role in fat mobilization and FAO. $(128,129)$ The regulation of PGC-1 $\alpha$ activity also suggests a role for SIRT in the generation of new mitochondria, as PGC- $1 \alpha$ is a key regulator of mitochondrial biogenesis. These observations, coupled with recent links between SIRT1 and autophagy (130), suggest that SIRT might regulate the flux of mitochondria within cells by balancing PGC-1 $\alpha$ mediated generation with autophagy-dependent clearance. In addition to the connection between SIRT1 and the mitochondria, SIRT3-dependent deacetylation regulates the activity of the mitochondrial enzyme acetyl coenzyme A synthetase 2 (AceCS2) $(131,132)$ as well as Complex I of ETC. Mitochondrial lysates from SIRT3 ${ }^{-/}$mice reveal $>30$ proteins whose acetylation is markedly increased, suggesting that other important targets undoubtedly exist. $(133,134)$ Finally, a very recent study has implicated SIRT5, another mitochondrial SIRT, as an important regulator of the urea cycle.(135)

In mice treatment with resveratrol, (3,5,4'-trihydroxystil- bene), a diet-derived polyphenol, improved mitochondrial function and biogenesis in the skeletal muscle (114) and the liver (136). Studies in diabetic mice demonstrated that resveratrol treatment improves endothelial function and attenuates vascular inflammation in diabetes mellitus (137-141) and extends longevity

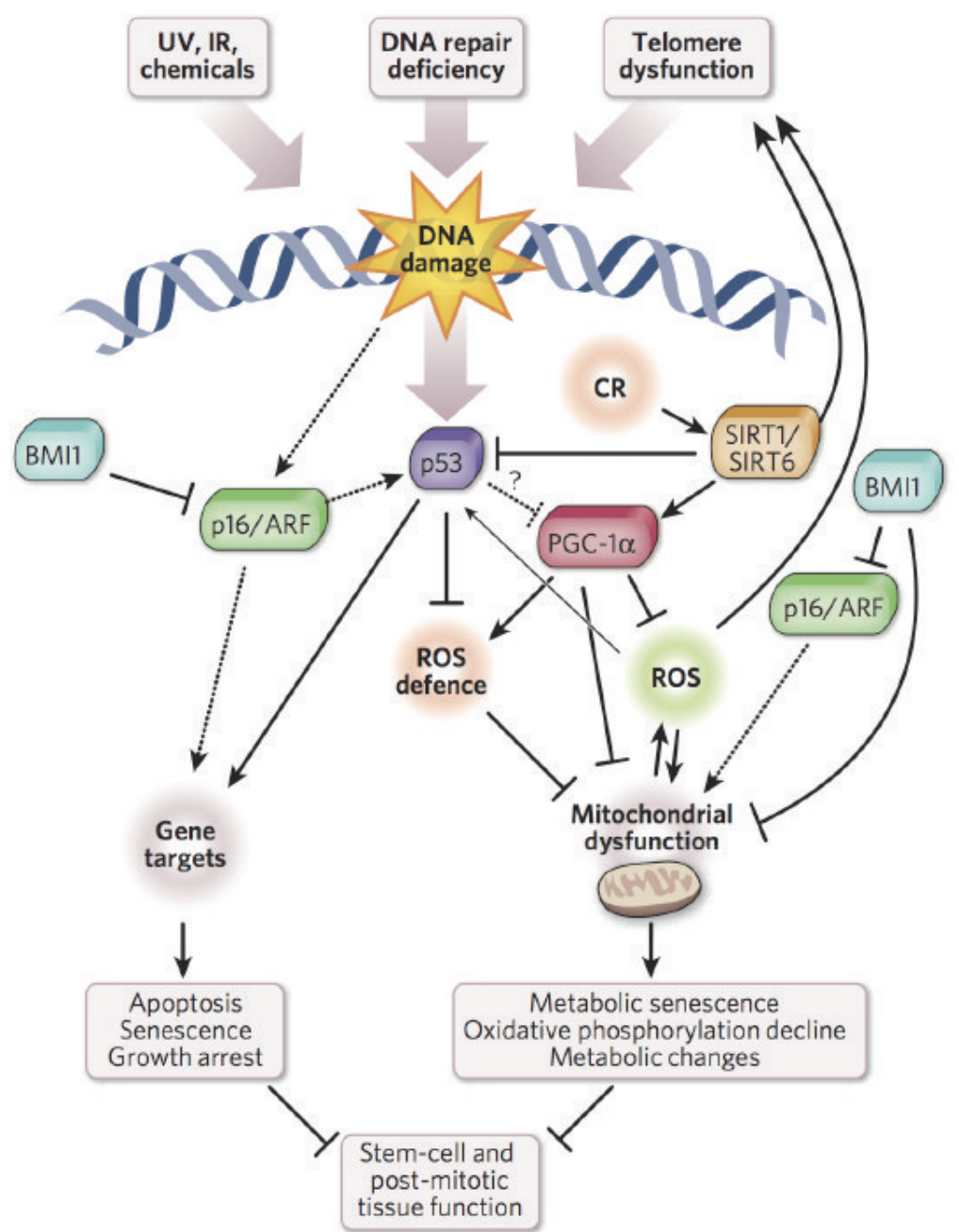

Figure 5. A model of interaction between DNA damage, p53 activation and mitochondrial dysfunction.(17) (Adapted with permission from Nature Publishing Group). 
$(136,142)$. Similar protective effects of resveratrol treatment were observed in aged mice. $(137,142)$ As noted above, both diabetes and aging are characterized by impaired mitochondrial biogenesis.(143)

Resveratrol, at physiologically relevant concentrations (144), increases mitochondrial content in endothelial cells via activating SIRT1. SIRT1, via a pathway that involves upregulation of endothelial nitric oxide synthase (eNOS), induces mitochondrial biogenesis factors (including Nrf1, Tfam, and PGC-1 $\alpha$ ), and promoting mitochondrial biogenesis. The finding that resveratrol treatment induces mitochondrial biogenesis in the aortas of type 2 diabetic mice suggests the potential for $\mathrm{CR}$ mimetics to target endothelial mitochondria in metabolic diseases, and rejuvenate aging stem cells.(143) Translation of insights gained from developmental metabolomics paves the way for a novel paradigm in tailored rejuvenation/regeneration strategies aimed at restoring compromised stem cell metabolism in aging and disease.

\section{Conclusion}

Recent data suggest that we age, in part, because our selfrenewing stem cells grow old as a result of heritable intrinsic events, such as DNA damage, as well as extrinsic forces, such as changes in their supporting niches. Mechanisms that suppress the development of cancer, such as senescence and apoptosis, which rely on telomere shortening and the activities of p53 and p16INK4a, may also induce an unwanted consequence: a decline in the replicative function of certain stem-cell types with advancing age.

Age-associated telomere damage, diminution of telomere 'capping' function and associated p53 activation have emerged as prime instigators of a functional decline of tissue stem cells and of mitochondrial dysfunction that adversely affect renewal and bioenergetic support in diverse tissues. Constructing a model of how telomeres, stem cells and mitochondria interact with key molecules governing genome integrity, 'stemness' and metabolism provides a framework for how diverse factors contribute to aging and age-related disorders.

The need to develop therapeutic strategies to treat pathophysiological conditions in the elderly is therefore medically, socially, and economically crucial. Characterization of normal stem cell aging is the critical first step toward achieving these goals as such research should be able to identify the mechanisms underlying stem cell functional decline and inform strategies for intervention.

\section{References}

1. Kirkwood TB. Understanding the odd science of aging. Cell. 2005; 120: 437-47.

2. Trivunovic A, Larsson NG. Mitochondrial dysfunction as a cause of ageing. J Intern Med. 2008; 263: 167-78.

3. Sohal RS, Orr WC. The redox stress hypothesis of aging. Free Radic Biol Med. 2012; 52: 539-55.

4. Marcinek DJ, Siegel MP. Targeting redox biology to reverse mitochondrial dysfunction. Aging (Albany NY). 2013; 5: 588-9.

5. Valko M, Leibfritz D, Moncol J, Cronin MT, Mazur M, Telser J. Free radicals and antioxidants in normal physiological functions and human disease. Int J Biochem Cell Biol. 2007; 39: 44-84.

6. Finkel T, Holbrook NJ. Oxidants, oxidative stress and the biology of ageing. Nature. 2000; 408: 239-47.

7. Ji J, Sharma V, Qi S, Guarch ME, Zhao P, Luo Z, et al. Antioxidant supplementation reduces genomic aberrations in human induced pluripotent stem cells. Stem Cell Reports. 2014; 2: 44-51.

8. Prigione A, Adjaye J. A mitochondrial strategy for safeguarding the reprogrammed genome. Cell Regen (Lond). 2014; 3: 5. doi: 10.1186/2045-9769-3-5.

9. Schlessinger D, Van Zant G. Does functional depletion of stem cells drive aging? Mech Ageing Dev. 2001; 122: 1537-53.

10. Park Y, Gerson SL. DNA repair defects in stem cell function and aging. Annu Rev Med. 2005; 56: 495-508.

11. Rossi DJ, Bryder D, Seita J, Nussenzweig A, Hoeijmakers J, Weissman IL. Deficiencies in DNA damage repair limit the function of haematopoietic stem cells with age. Nature. 2007; 447: 725-9.

12. Hamanaka RB, Chandel NS. Mitochondrial reactive oxygen species regulate cellular signaling and dictate biological outcomes. Trends Biochem Sci. 2010; 35: 505-13.

13. Ito K, Hirao A, Arai F, Matsuoka S, Takubo K, Hamaguchi I, et al. Regulation of oxidative stress by ATM is required for self-renewal of haematopoietic stem cells. Nature. 2004; 431: 997-1002.

14. Narasimhaiah R, Tuchman A, Lin SL, Naegele JR. Oxidative damage and defective DNA repair is linked to apoptosis of migrating neurons and progenitors during cerebral cortex development in Ku70-deficient mice. Cereb Cortex. 2005; 15: 696-707.

15. Ahlqvist KJ, Hämäläinen RH, Yatsuga $\mathrm{S}$, Uutela $\mathrm{M}$, Terzioglu M, Götz A, et al. Somatic progenitor cell vulnerability to mitochondrial DNA mutagenesis underlies progeroid phenotypes in Polg mutator mice. Cell Metab. 2012; 15: 100-9.

16. Nunnari J, Suomalainen A. Mitochondria: in sickness and in health. Cell. 2012; 148: 1145-59.

17. Sahin E, Depinho RA. Linking functional decline of telomeres, mitochondria and stem cells during ageing. Nature. 2010; 464: 5208.

18. Rossi DJ, Jamieson CHM, Weissman IL. Stems cells and the pathways to aging and cancer. Cell. 2008; 132: 681-96.

19. Van Zant G, Liang Y. The role of stem cells in aging. Exp Hematol. 2003; 31: 659-72.

20. Chambers SM, Shaw CA, Gatza C, Fisk CJ, Donehower LA, Goodell MA. Aging hematopoietic stem cells decline in function and exhibit epigenetic dysregulation. PLoS Biol. 2007; 5: e201.

21. Hodgson GS, Bradley TR. In vivo kinetic status of hematopoietic stem and progenitor cells as inferred from labeling with bromodeoxyuridine. Exp Hematol. 1984; 12: 683-7.

22. Passegue E, Wagers AJ, Giuriato S, Anderson WC, Weissman IL. Global analysis of proliferation and cell cycle gene expression in 
the regulation of hematopoietic stem and progenitor cell fates. J Exp Med. 2005; 202: 1599-611.

23. Sharpless NE, DePinho RA. How stem cells age and why this makes us grow old. Nat Mol Cell Biol. 2007; 8: 703-13.

24. Rossi DJ, Bryder D, Zahn JM, Ahlenius H, Sonu R, Wagers AJ, et al. Cell intrinsic alterations underlie hematopoietic stem cell aging. Proc Natl Acad Sci USA. 2005; 102: 9194-9.

25. Sharpless NE, Depinho RA. Telomeres, stem cells, senescence, and cancer. J Clin Invest. 2004; 113: 160-8.

26. Reya T, Morrison SJ, Clarke MF, Weissman IL. Stem cells, cancer, and cancer stem cells. Nature. 2001; 414: 105-11.

27. Campisi J. Cancer and ageing: rival demons? Nature Rev Cancer. 2003; 3: 339-49.

28. Finkel T, Serrano M, Blasco MA. The common biology of cancer and ageing. Nature. 2007; 448: 767-74.

29. Kluge MA, Fetterman JL, Vita JA. Mitochondria and Endothelial Function. Circ Res. 2013; 112: 1171-88.

30. Wallace DC. A mitochondrial bioenergetic etiology of disease. J Clin Invest. 2013; 123: 1405-12.

31. Galluzzi L, Joza N, Tasdemir E, Maiuri MC, Hengartner M, Abrams $\mathrm{JM}$, et al. No death without life: vital functions of apoptotic effectors. Cell Death Differ. 2008; 15: 1113-23.

32. Galluzzi L, Kepp O, Trojel-Hansen C, Kroemer G. Non-apoptotic functions of apoptosis-regulatory proteins. EMBO Rep. 2012; 13: 322-30.

33. Sagan L. On the origin of mitosing cells. J Theor Biol. 1967; 14: 25574.

34. Kroemer G, Mariño G, Levine B. Authophagy and the integrated stress response. Mol Cell. 2010; 40: 280-93.

35. Youle RJ, Narendra DP. Mechanisms of mitophagy. Nat Rev Mol Cell Biol. 2011; 12: 9-14.

36. Galluzzi L, Kepp O, Kroemer G. Mitochondrial dynamics: a strategy for avoiding autophagy. Curr Biol. 2011; 21: R478-80.

37. Gomes LC, Di Benedetto G, Scorrano L. During autophagy mitochondria elongate, are spared from degradation and sustain cell viability. Nat Cell Biol. 2011; 13: 589-98.

38. Dalton TP, Shertzer HG, Puga A. Regulation of gene expression by reactive oxygen. Annu Rev Pharmacol Toxicol. 1999; 39: 67-101.

39. Balaban RS, Nemoto S, Finkel T. Mitochondria, oxidants, and aging. Cell. 2005; 120: 483-95.

40. Galluzzi L, Kepp O, Trojel-Hansen C, Kroemer G. Mitochondrial control of cellular life, stress, and death. Circ Res. 2011; 111: 1198207.

41. Wajant $\mathrm{H}$. The Fas signaling pathway: more than a paradigm. Science. 2002; 296: 1635-6.

42. Mehlen P. Dependence receptors: the trophic theory revisited. Sci Signal. 2010; 3: pe47. doi: 10.1126/scisignal.3151pe47.

43. Muzio M, Chinnaiyan AM, Kischkel FC, O'Rourke K, Shevchenko A, Ni J, et al. FLICE, a novel FADD-homologous ICE/CED-3- like protease, is recruited to the CD95 (Fas/APO-1) death-inducing signaling complex. Cell. 1996; 85: 817-27.

44. Degterev A, Hitomi J, Germscheid M, Ch'en IL, Korkina O, Teng $\mathrm{X}$, et al. Identification of RIP1 kinase as a specific cellular target of necrostatins. Nat Chem Biol. 2008; 4: 313-21.

45. Galluzzi L, Vanden Berghe T, Vanlangenakker N, Buettner S, Eisenberg T, Vandenabeele P, et al. Programmed necrosis from molecules to health and disease. Int Rev Cell Mol Biol. 2011; 289: $1-35$.

46. Cho YS, Challa S, Moquin D, Genga R, Ray TD, Guildford M, et al. Phosphorylation-driven assembly of the RIP1-RIP3 complex regulates programmed necrosis and virus-induced inflammation. Cell. 2009; 137: 1112-23.
47. He S, Wang L, Miao L, Wang T, Du F, Zhao L, et al. Receptor interacting protein kinase-3 determines cellular necrotic response to TNF- alpha. Cell. 2009; 137: 1100-11.

48. Zhang DW, Shao J, Lin J, Zhang N, Lu BJ, Lin SC, et al. RIP3, an energy metabolism regulator that switches TNF-induced cell death from apoptosis to necrosis. Science. 2009; 325: 332-6.

49. Zong WX, Ditsworth D, Bauer DE, Wang ZQ, Thompson CB. Alkylating DNA damage stimulates a regulated form of necrotic cell death. Genes Dev. 2004; 18: 1272-82.

50. Wenz T. Regulation of mitochondrial biogenesis and PGC-1 $\alpha$ under cellular stress. Mitochondrion. 2013; 13: 134-42.

51. Dutta D, Calvani R, Bernabei R, Leeuwenburgh C, Marzetti E. Contribution of Impaired Mitochondrial Autophagy to Cardiac Aging. Mechanisms and therapeutic opportunities. Circ Res. 2012; 110: $1125-38$.

52. Scarpulla RC. Metabolic control of mitochondrial biogenesis through the PGC-1 family regulatory network. Biochim Biophys Acta. 2011; 1813: 1269-78.

53. Ding G, Fu M, Qin Q, Lewis W, Kim HW, Fukai T, et al. Cardiac peroxisome proliferator-activated receptor gamma is essential in protecting cardio-myocytes from oxidative damage. Cardiovasc Res. 2007; 76: 269-79.

54. Garnier A, Fortin D, Zoll J, N'Guessan B, Mettauer B, Lampert E, et al. Coordinated changes in mitochondrial function and biogenesis in healthy and diseased human skeletal muscle. FASEB J. 2005; 19: 43-52.

55. Bereiter-Hahn J. Behavior of mitochondria in the living cell. Int Rev Cytol. 1990; 122: 1-63.

56. Hoppins S, Lackner L, Nunnari J. The machines that divide and fuse mitochondria. Annu Rev Biochem. 2007; 76: 751-80.

57. Chan DC. Mitochondria: dynamic organelles in disease, aging, and development. Cell. 2006; 125: 1241-52.

58. Bach D, Pich S, Soriano FX, Vega N, Baumgartner B, Oriola J, et al. Mitofusin-2 determines mitochondrial network architecture and mitochondrial metabolism. A novel regulatory mechanism altered in obesity. J Biol Chem. 2003; 278: 17190-7.

59. Soriano FX, Liesa M, Bach D, Chan DC, Palacin M, Zorzano A. Evidence for a mitochondrial regulatory pathway defined by peroxisome proliferator-activated receptor-gamma coactivator-1 alpha, estrogen-related receptor-alpha, and mitofusin-2. Diabetes. 2006; 55: 1783-91.

60. Till A, Subramani S. A balancing art for autophagin. J Clin Invest. 2010; 120: 2273-6.

61. Ashrafi G, Schwarz TL. The pathways of mitophagy for quality control and clearance of mitochondria. Cell Death and Differ. 2013; 20: $31-42$.

62. Wallace DC. A mitochondrial paradigm of metabolic and degenerative diseases, aging, and cancer: a dawn for evolutionary medicine. Annu Rev Genet. 2005; 39: 359-407.

63. Dai DF, Rabinovitch PS, Ungvari Z. Mitochhondria and cardiovascular aging. Circ Res. 2012; 110: 1109-24.

64. Csiszar A, Labinskyy N, Jimenez R, Pinto JT, Ballabh P, Losonczy G, et al. Anti-oxidative and anti-inflammatory vasoprotective effects of caloric restriction in aging: role of circulating factors and SIRT1. Mech Ageing Dev. 2009; 130: 518-27.

65. van der Loo B, Labugger R, Skepper JN, Bachschmid M, Kilo J, Powell JM, et al. Enhanced peroxynitrite formation is associated with vascular aging. J Exp Med. 2000; 192: 1731-44.

66. Ungvari ZI, Labinskyy N, Gupte SA, Chander PN, Edwards JG, Csiszar A. Dysregulation of mitochondrial biogenesis in vascular endothelial and smooth muscle cells of aged rats. Am J Physiol Heart Circ Physiol. 2008; 294: H2121-8. 
67. Ungvari Z, Kaley G, de Cabo R, Sonntag WE, Csiszar A. Mechanisms of vascular aging: new perspectives. J Gerontol A Biol Sci Med Sci. 2010; 65: 1028-41.

68. Csiszar A, Labinskyy N, Podlutsky A, Kaminski PM, Wolin MS, Zhang $\mathrm{C}$, et al. Vasoprotective effects of resveratrol and SIRT1: attenuation of cigarette smoke-induced oxidative stress and proinflammatory phenotypic alterations. Am J Physiol Heart Circ Physiol. 2008; 294: H2721-35.

69. Labinskyy N, Mukhopadhyay P, Toth J, Szalai G, Veres M, Losonczy $\mathrm{G}$, et al. Longevity is associated with increased vascular resistance to high glucose-induced oxidative stress and inflammatory gene expression in Peromyscus leucopus. Am J Physiol Heart Circ Physiol. 2009; 296: H946-56.

70. Johri A, Beal MF. Mitochondrial Dysfunction in Neurodegenerative Diseases. J Pharmacol Exp Ther. 2012; 342: 619-30.

71. De Coo IF, Renier WO, Ruitenbeek W, Ter Laak HJ, Bakker M, Schagger $\mathrm{H}$, et al. A 4-base pair deletion in the mitochondrial cytochrome $\mathrm{b}$ gene associated with parkinsonism/MELAS overlap syndrome. Ann Neurol. 1999; 45: 130-3.

72. Coskun PE, Beal MF, Wallace DC. Alzheimer's brains harbor somatic mtDNA control-region mutations that suppress mitochondrial transcription and replication. Proc Natl Acad Sci USA. 2004; 101: 10726-31.

73. Smigrodzki R, Parks J, Parker WD. High frequency of mitochondrial complex I mutations in Parkinson's disease and aging. Neurobiol Aging. 2004; 25: 1273-81.

74. Parker WD Jr, Parks JK. Mitochondrial ND5 mutations in idiopathic Parkinson's disease. Biochem Biophys Res Commun. 2005; 326: 667-9.

75. Bender A, Krishnan KJ, Morris CM, Taylor GA, Reeve AK, Perry $\mathrm{RH}$, et al. High levels of mitochondrial DNA deletions in substantia nigra neurons in aging and Parkinson disease. Nat Genet. 2006; 38: 515-7.

76. Bender A, Schwarzkopf RM, McMillan A, Krishnan KJ, Rieder G, Neumann M, et al. Dopaminergic midbrain neurons are the prime target for mitochondrial DNA deletions. J Neurol. 2008; 255: 12315.

77. Reeve AK, Krishnan KJ, Elson JL, Morris CM, Bender A, Lightowlers $\mathrm{RN}$, et al. Nature of mitochondrial DNA deletions in substantia nigra neurons. Am J Hum Genet. 2008; 82: 228-35.

78. Austin S, St-Pierre J. PGC1 $\alpha$ and mitochondrial metabolism-emerging concepts and relevance in ageing and neurodegenerative disorders. J Cell Sci. 2012; 125: 4963-71.

79. Lin MT, Beal MF. Mitochondrial dysfunction and oxidative stress in neurodegenerative diseases. Nature. 2006; 443: 787-95.

80. Zheng B, Liao Z, Locascio JJ, Lesniak KA, Roderick SS, Watt ML, et al. PGC-1 $\alpha$, a potential therapeutic target for early intervention in Parkinson's disease. Sci Transl Med. 2010; 2: 52ra73. doi: 10.1126/ scitranslmed.3001059.

81. St-Pierre J, Drori S, Uldry M, Silvaggi JM, Rhee J, Jäger S, et al. Suppression of reactive oxygen species and neurodegeneration by the PGC-1 transcriptional coactivators. Cell. 2006; 127: 397-408.

82. Wareski P, Vaarmann A, Choubey V, Safiulina D, Liiv J, Kuum M, et al. PGC-1 \{alpha\} and PGC-1 \{beta\} regulate mitochondrial density in neurons. J Biol Chem. 2009; 284: 21379-85.

83. Gong B, Chen F, Pan Y, Arrieta-Cruz I, Yoshida Y, Haroutunian V, et al. SCFFbx2-E3-ligase-mediated degradation of BACE1 attenuates Alzheimer's disease amyloidosis and improves synaptic function. Aging Cell. 2010; 9: 1018-31.

84. Qin W, Haroutunian V, Katsel P, Cardozo CP, Ho L, Buxbaum JD, et al. PGC-1alpha expression decreases in the Alzheimer disease brain as a function of dementia. Arch Neurol. 2009; 66: 352-61.
85. Sheng B, Wang X, Su B, Lee HG, Casadesus G, Perry G, et al. Impaired mitochondrial biogenesis contributes to mitochondrial dysfunction in Alzheimer's disease. J Neurochem. 2012; 120: 41929.

86. Da Cruz S, Parone PA, Lopes VS, Lillo C, McAlonis-Downes M, Lee SK, et al. Elevated PGC-1 $\alpha$ activity sustains mitochondrial biogenesis and muscle function without extending survival in a mouse model of inherited ALS. Cell Metab. 2012; 15: 778-86.

87. Liang H, Ward WF, Jang YC, Bhattacharya A, Bokov AF, Li Y, et al. PGC- $1 \alpha$ protects neurons and alters disease progression in an amyotrophic lateral sclerosis mouse model. Muscle Nerve. 2011; 44: 947-56.

88. Zhao W, Varghese M, Yemul S, Pan Y, Cheng A, Marano P, et al. Peroxisome proliferator activator receptor gamma coactivator1alpha (PGC-1 $\alpha$ ) improves motor performance and survival in a mouse model of amyotrophic lateral sclerosis. Mol Neurodegener. 2011; 6: 51. doi: 10.1186/1750-1326-6-51.

89. Handschin C, Kobayashi YM, Chin S, Seale P, Campbell KP, Spiegelman BM. PGC-1alpha regulates the neuromuscular junction program and ameliorates Duchenne muscular dystrophy. Genes Dev. 2007; 21: 770-83.

90. Trounce I, Byrne E, Marzuki S. Decline in skeletal muscle mitochondrial respiratory chain function: possible factor in ageing. Lancet. 1989; 1: 637-9.

91. Yen TC, Chen YS, King KL, Yeh SH, Wei YH. Liver mitochondrial respiratory functions decline with age. Biochem Biophys Res Commun. 1989; 165: 994-1003.

92. Linnane AW, Marzuki S, Ozawa T, Tanaka M. Mitochondrial DNA mutations as an important contributor to ageing and degenerative diseases. Lancet 1989; 1: 642-5.

93. Liu L, Rando TA. Manifestations and mechanisms of stem cell aging. J Cell Biol. 2011; 193: 257-66.

94. Conboy IM, Conboy MJ, Wagers AJ, Girma ER, Weissman IL, Rando TA. Rejuvenation of aged progenitor cells by exposure to a young systemic environment. Nature. 2005; 433: 760-4.

95. Folmes CDL, Dzeja PP, Nelson TJ, Terzic A. Metabolic plasticity in stem cell homeostasis and differentiation. Cell Stem Cell. 2012; 11: 596-606.

96. Chung S, Dzeja PP, Faustino RS, Perez-Terzic C, Behfar A, Terzic A. Mitochondrial oxidative metabolism is required for the cardiac differentiation of stem cells. Nat Clin Pract Cardiovasc Med. 2007; 4 (Suppl 1): S60-7.

97. Lonergan T, Brenner C, Bavister B. Differentiation-related changes in mitochondrial properties as indicators of stem cell competence. J Cell Physiol. 2006; 208: 149-53.

98. San Martin N, Cervera AM, Cordova C, Covarello D, McCreath KJ, Galvez BG. Mitochondria determine the differentiation potential of cardiac mesoangioblasts. Stem Cells. 2011; 29: 1064-74.

99. Chen CT, Shih YR, Kuo TK, Lee OK, Wei YH. Coordinated changes of mitochondrial biogenesis and antioxidant enzymes during osteogenic differentiation of human mesenchymal stem cells. Stem Cells. 2008; 26: 960-8.

100. Cho YM, Kwon S, Pak YK, Seol HW, Choi YM, Park do J, et al. Dynamic changes in mitochondrial biogenesis and antioxidant enzymes during the spontaneous differentiation of human embryonic stem cells. Biochem Biophys Res Commun. 2006; 348 : $1472-8$.

101. Facucho-Oliveira JM, Alderson J, Spikings EC, Egginton S, St John JC. Mitochondrial DNA replication during differentiation of murine embryonic stem cells. J Cell Sci. 2007; 120: 4025-34.

102. Tormos KV, Anso E, Hamanaka RB, Eisenbart J, Joseph J, Kalyanaraman B, et al. Mitochondrial complex III ROS regulate 
adipocyte differentiation. Cell Metab. 2011; 14: 537-44.

103. Jasper H, Jones DL. Metabolic regulation of stem cell behavior and implications for aging. Cell Metab. 2010; 12: 561-5.

104. Renault VM, Rafalski VA, Morgan AA, Salih DA, Brett JO, Webb $\mathrm{AE}$, et al. FoxO3 regulates neural stem cell homeostasis. Cell Stem Cell. 2009; 5: 527-39.

105. Shim J, Mukherjee T, Banerjee U. Direct sensing of systemic and nutritional signals by haematopoietic progenitors in Drosophila. Nat Cell Biol. 2012; 14: 394-400.

106. Chen C, Liu Y, Liu Y, Zheng P. mTOR regulation and therapeutic rejuvenation of aging hematopoietic stem cells. Sci Signal. 2009; 2: ra75. doi: 10.1126/scisignal.2000559.

107. Harrison DE, Strong R, Sharp ZD, Nelson JF, Astle CM, Flurkey $\mathrm{K}$, et al. Rapamycin fed late in life extends lifespan in genetically heterogeneous mice. Nature. 2009; 460: 392-5.

108. Zong H, Ren JM, Young LH, Pypaert M, Mu J, Birnbaum MJ, et al. AMP kinase is required for mitochondrial biogenesis in skeletal muscle in response to chronic energy deprivation. Proc Natl Acad Sci USA. 2002; 99: 15983-7.

109. Suwa M, Nakano H, Kumagai S. Effects of chronic AICAR treatment on fiber composition, enzyme activity, UCP3, and PGC-1 in rat muscles. J Appl Physiol. 2003; 95: 960-8.

110. Jager S, Handschin C, St-Pierre J, Spiegelman BM. AMP-activated protein kinase (AMPK) action in skeletal muscle via direct phosphorylation of PGC-1alpha. Proc Natl Acad Sci USA. 2007; 104: 12017-22.

111. Rodgers JT, Lerin C, Haas W, Gygi SP, Spiegelman BM, Puigserver P. Nutrient control of glucose homeostasis through a complex of PGC-1alpha and SIRT1. Nature. 2005; 434: 113-8.

112. Gerhart-Hines Z, Rodgers JT, Bare O, Lerin C, Kim SH, Mostoslavsky $\mathrm{R}$, et al. Metabolic control of muscle mitochondrial function and fatty acid oxidation through SIRT1/PGC-1alpha. EMBO J. 2007; 26: 1913-23.

113. Nemoto S, Fergusson MM, Finkel T. SIRT1 functionally interacts with the metabolic regulator and transcriptional coactivator PGC1 \{alpha\}. J Biol Chem. 2005; 280: 16456-60.

114. Lagouge M, Argmann C, Gerhart-Hines Z, Meziane H, Lerin C, Daussin F, et al. Resveratrol improves mitochondrial function and protects against metabolic disease by activating SIRT1 and PGC1alpha. Cell. 2006; 127: 1109-22.

115. Canto C, Gerhart-Hines Z, Feige ZN, Lagouge M, Noriega L, Milne JC, et al. AMPK regulates energy expenditure by modulating NAD+ metabolism and SIRT1 activity. Nature. 2009; 458: 1056-60.

116. Tothova Z, Kollipara R, Huntly BJ, Lee BH, Castrillon DH, Cullen DE, et al. FoxOs are critical mediators of hematopoietic stem cell resistance to physiologic oxidative stress. Cell. 2007; 128: 325-39.

117. Sherwood SW, Rush D, Ellsworth JL, Schimke RT. Defining cellular senescence in IMR-90 cells: a flow cytometric analysis. Proc Natl Acad Sci USA. 1988; 85: 9086-90.

118. Kuilman T, Michaloglou C, Mooi WJ, Peeper DS. The essence of senescence. Genes Dev. 2010; 24: 2463-79.

119. Rufini A, Tucci P, Celardo I, Melino G. Senescence and aging: the critical roles of p53. Oncogene. 2013; 32: 5129-43.

120. Guarente L. Mitochondria - a nexus for aging, calorie restriction, and sirtuins? Cell. 2008; 132: 171-6.

121. Sablina AA, Budanov AV, Ilyinskaya GV, Agapova LS, Kravchenko JE, Chumakov PM. The antioxidant function of the p53 tumor suppressor. Nature Med. 2005; 11: 1306-13.

122. Kim WY, Sharpless NE. The regulation of INK4/ARF in cancer and aging. Cell. 2006; 127: 265-75.

123. Liu J, Cao L, Chen J, Song S, Lee IH, Quijano C, et al. Bmi1 regulates mitochondrial function and the DNA damage response pathway.
Nature. 2009; 459: 387-92.

124. Spees JL, Olson SD, Whitney MJ, Prockop DJ. Mitochondrial transfer between cells can rescue aerobic respiration. Proc Natl Acad Sci USA. 2006; 103: 1283-8.

125. Islam MN, Das SR, Emin MT, Wei M, Sun L, Westphalen K, et al. Mitochondrial transfer from bone-marrow-derived stromal cells to pulmonary alveoli protects against acute lung injury. Nat Med. 2012; 18: 759-65.

126. Cerletti M, Jang YC, Finley LW, Haigis MC, Wagers AJ. Short-term calorie restriction enhances skeletal muscle stem cell function. Cell Stem Cell. 2012; 10: 515-9.

127. Finkel T, Deng CX, Mostoslavsky R. Recent progress in the biology and physiology of sirtuins. Nature. 2009; 460: 587-91.

128. Feige JN, Auwerx J. Transcriptional targets of sirtuins in the coordination of mammalian physiology. Curr Opin Cell Biol. 2008; 20: 303-9.

129. Rodgers JT, Lerin C, Gerhart-Hines Z, Puigserver P. Metabolic adaptations through the PGC-1 alpha and SIRT1 pathways. FEBS Lett. 2008; 582: 46-53.

130. Lee IH, Cao L, Mostoslavsky R, Lombard DB, Liu J, Bruns NE, et al. A role for the NAD-dependent deacetylase Sirt1 in the regulation of autophagy. Proc Natl Acad Sci USA. 2008; 105: 3374-9.

131. Schwer B, Bunkenborg J, Verdin RO, Andersen JS, Verdin E. Reversible lysine acetylation controls the activity of the mitochondrial enzyme acetyl-CoA synthetase 2. Proc Natl Acad Sci USA. 2006; 103: 10224-9.

132. Hallows WC, Lee S, Denu JM. Sirtuins deacetylate and activate mammalian acetyl-CoA synthetases. Proc Natl Acad Sci USA. 2006; 103: 10230-5.

133. Ahn BH, Kim HS, Song S, Lee IH, Liu J, Vassilopoulos A, et al. A role for the mitochondrial deacetylase Sirt3 in regulating energy homeostasis. Proc Natl Acad Sci USA. 2008; 105: 14447-52.

134. Lombard DB, Alt FW, Cheng HL, Bunkenborg J, Streeper RS, Mostoslavsky R, et al. Mammalian Sir2 homolog SIRT3 regulates global mitochondrial lysine acetylation. Mol Cell Biol. 2007; 27: 8807-14.

135. Nakagawa T, Lomb DJ, Haigis MC, Guarente L. SIRT5 deacetylates carbamoyl phosphate synthetase 1 and regulates the urea cycle. Cell. 2009; 137: 560-70.

136. Baur JA, Pearson KJ, Price NL, Jamieson HA, Lerin C, Kalra A, et al. Resveratrol improves health and survival of mice on a high-calorie diet. Nature. 2006; 444: 337-42.

137. Pearson KJ, Baur JA, Lewis KN, Peshkin L, Price NL, Labinskyy $\mathrm{N}$, et al. Resveratrol delays age-related deterioration and mimics transcriptional aspects of dietary restriction without extending life span. Cell Metab. 2008; 8: 157-68.

138. Sharma S, Anjaneyulu M, Kulkarni SK, Chopra K. Resveratrol, a polyphenolic phytoalexin, attenuates diabetic nephropathy in rats. Pharmacology. 2006; 76: 69-75.

139. Su HC, Hung LM, Chen JK. Resveratrol, a red wine antioxidant, possesses an insulin-like effect in streptozotocin-induced diabetic rats. Am J Physiol Endocrinol Metab. 2006; 290: E1339-46.

140. Thirunavukkarasu M, Penumathsa SV, Koneru S, Juhasz B, Zhan $\mathrm{L}$, Otani $\mathrm{H}$, et al. Resveratrol alleviates cardiac dysfunction in streptozotocin-induced diabetes: role of nitric oxide, thioredoxin, and heme oxygenase. Free Radic Biol Med. 2007; 43: 720-9.

141. Zang M, Xu S, Maitland-Toolan KA, Zuccollo A, Hou X, Jiang B, et al. Polyphenols stimulate AMP-activated protein kinase, lower lipids, and inhibit accelerated atherosclerosis in diabetic LDL receptor-deficient mice. Diabetes. 2006; 55: 2180-91.

142. Ungvari ZI, Orosz Z, Labinskyy N, Rivera A, Xiangmin Z, Smith $\mathrm{KE}$, et al. Increased mitochondrial $\mathrm{H} 2 \mathrm{O} 2$ production promotes 
endotheial NF-kappaB activation in aged rat arteries. Am J Physiol Heart Circ Physiol. 2007; 293: H37-47.

143. Csiszar A, Labinsky N, Pinto JT, Ballabh P, Zhang H, Losonczy G, et al. Resveratrol induces mitochondrial biogenesis in endothelial cells. Am J Physiol Heart Circ Physiol. 2009; 297: H13-20.

144. Baur JA, Sinclair DA. Therapeutic potential of resveratrol: the in vivo evidence. Nat Rev Drug Discov. 2006; 5: 493-506. 